Journal of Reproduction and Development, Vol. 39, No. 4, 1993

\title{
Penetration of the Zona Pellucida of Eggs of Different Species by Spermatozoa of the Japanese Field Vole, Microtus montebelli
}

\author{
Teruhiko WAKAYAMA ${ }^{1) *}$, Yuko MARUYAMA ${ }^{2)}$, \\ Kenkichi IMAMURA ${ }^{2)}$ and Katsuhiro FUKUTA ${ }^{2)}$ \\ ${ }^{1)}$ Faculty of Agriculture, Ibaraki University, \\ Ami-machi, Inashiki-gun, Ibaraki 300-03, and \\ ${ }^{2)}$ National Institute of Animal Health, Tsukuba, \\ Ibaraki 305, Japan
}

\begin{abstract}
Penetration of the zona pellucida of heterologous eggs by spermatozoa of Japanese field vole, Microtus montebelli, was examined in vitro. Spermatozoa from the vole epididymis were more active and survived longer in mKRB medium than did mouse spermatozoa. When vole spermatozoa were used for insemination, they passed through the zona pellucida of mouse and hamster eggs at a high rate. Although many spermatozoa invaded the perivitelline space of such eggs, penetration of the vitelline membrane was not confirmed. The present result suggests that vole spermatozoa have a high ability to penetrate zona pellucida of heterologous eggs.

Key words: Japanese field vole, Zona pellucida, Spermatozoa, Penetration.
\end{abstract}

(J. Reprod. Dev. 39: 319-323, 1993)

$\mathbf{T}$ echniques of in vitro fertilization enable us to investigate direct interactions between sperm and eggs. Examination of the interaction between sperm and eggs of different species that normally do not occur is also possible. In general, the invasion of eggs by heterologous sperm is prevented by the barrier known as the zona pellucida [1]. In studies of in vitro insemination with sperm and eggs from different mammalian species, zonafree eggs of a few species were invaded by heterologous spermatozoa [2-4]. Significant penetration of intact ova from different species were reported for spermatozoa of the deer mouse and laboratory mouse. Deer mice sperm were able to penetrate the zona pellucida of $21 \%$ of mouse

Accepted for Publication: June 25, 1993

Correspondence: $T$. Wakayama eggs [5] and $14 \%$ of rat eggs [6]; mouse sperm were able to penetrate the zona pellucida of $6 \%$ of rat eggs [6]. However, their entry into oocytes was blocked by the vitelline membrane.

The Japanese field vole, Microtus montebelli, is a herbivorous rodent. Captive voles were bred as possible candidates for experimental use in the hope that they might replace herbivorous domestic animals $[7,8]$. In the present paper, we describe how the vigorous spermatozoa of Japanese field vole were able to penetrate the zona pellucida of both mouse and hamster eggs.

\section{Materials and Methods}

Japanese field voles used in the present study were initially captured in the wild and maintained 
at the National Institute of Animal Health for more than 15 years by outbred mating. Fourteen mature male voles were sacrificed by cervical fracture, and the epididymis of each was removed. The caudal portion of the epididymis was cut, and clusters of sperm were placed in culture medium.

TYH medium, designed for mouse sperm [9], and mKRB medium, designed for rat sperm [10], were prepared to examine the viability and motility of vole sperm. Aliquots of $0.1 \mathrm{ml}$ of each medium were placed in a plastic petri dish $3 \mathrm{~cm}$ in diameter and covered with paraffin oil. Sperm were suspended in the media at concentrations of $1-2 \times 10^{8} / \mathrm{ml}$. The sperm suspensions were incubated in $5 \% \mathrm{CO}_{2}$ and $95 \%$ air at $37 \mathrm{C}$ for $0.5,3,6$, $9,12,18,24,30,36,42,48,54,60,66,72$, and 78 h. After incubation, $5 \mu \mathrm{l}$ of each suspension were placed on a glass slide. Motile and immotile sperm were counted to assess viability.

To examine penetration of the zona pellucida by vole spermatozoa, eggs were collected from outbred ICR mice and inbred albino Syrian hamsters. Two to 3 month old female ICR mice were induced to superovulate by injections of PMSG (5 IU) and hCG (5 IU) with a $48 \mathrm{~h}$ interval between injections. Eggs with follicular cells were collected from the swollen ampullae of oviducts $16 \mathrm{~h}$ after hCG injection. Female hamsters, 2 to 3 months old, were also induced to superovulate by injec- tions of PMSG (30 IU) and hCG (30 IU) with a 56 $h$ interval between injections, and eggs were collected $18 \mathrm{~h}$ after hCG injection. Half of the eggs were treated with a $0.1 \%(\mathrm{w} / \mathrm{v})$ solution of hyaluronidase to remove the follicular cells.

About 40 mouse eggs and 15 hamster eggs were placed in $0.1 \mathrm{ml}$ of mKRB medium, and vole sperm were then added at a concentration of $2 \times 10^{7}$ cells $/ \mathrm{ml}$ without preincubation for capacitaion. After 2 to $12 \mathrm{~h}$ of incubation, the eggs were observed under a phase-contrast microscope to monitor sperm penetration of the zona and formation of the pronucleus. Finally, eggs were fixed in $2.5 \%$ glutaraldehyde, stained with $0.25 \%$ acetolacmoid, and examined under the phase-contrast microscope. The penetration rate of intact and follicular cell-free eggs was statistically analyzed by the $\chi^{2}$ test.

\section{Results}

\section{Viability and motility of vole spermatozoa}

The survival of vole and mouse spermatozoa in TYH and mKRB media is illustrated in Fig. 1. The vole sperm in mKRB medium were active and survived for a long time. The survival of vole sperm in TYH was equivalent to $\mathrm{mKRB}$ for $12 \mathrm{~h}$, but survival decreased rapidly after $18 \mathrm{~h}$. Mouse

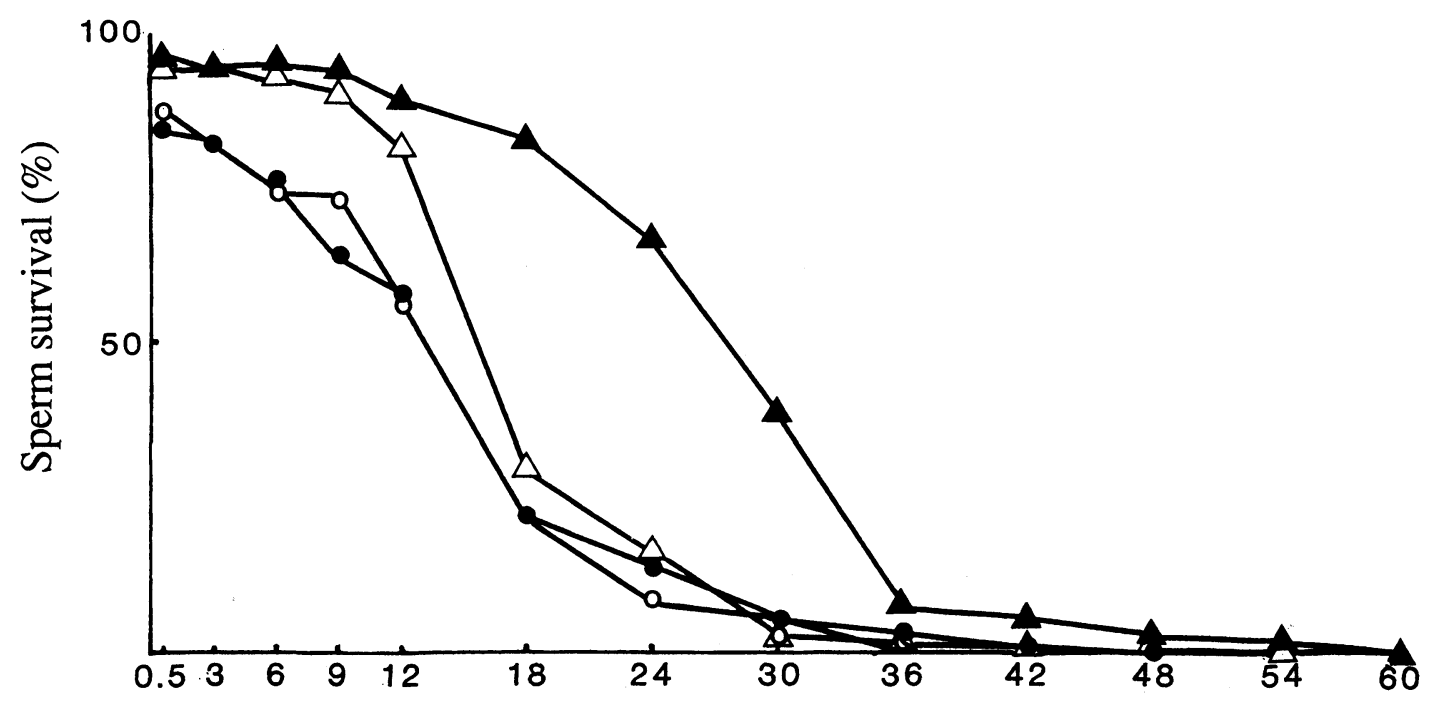

Incubation time $(\mathrm{h})$

Fig. 1. Survival of vole and mouse sperm in vitro. $\boldsymbol{\Delta}$, vole in mKRB; $\bullet$, mouse in mKRB; $\triangle$, vole in TYH; $\bigcirc$, mouse in TYH. 
sperm exhibited lower survival rates than the vole sperm, and the survival of mouse sperm was similar in the two media.

With respect to the motility of the spermatozoa, vole sperm in mKRB medium exhibited very active movement compared to mouse sperm. From 0.5 to $12 \mathrm{~h}$ in culture, the vole sperm exhibited characteristic circular movements on glass slides under the light microscope (Fig. 2). The circles of movement were $150-200 \mu \mathrm{m}$ in diameter, and they were described by a large number of sperm moving forward actively. After $12 \mathrm{~h}$ in culture the sperm began to aggregate head-to-head, and the aggregates increased in size with time.

Penetration of the zona pellucida of mouse and hamster eggs by vole spermatozoa

The results of in vitro insemination by vole sperm of mouse and hamster eggs are shown in Tables 1 and 2, respectively. Follicular cells surrounding eggs dispersed 2 to 3 minutes after the introduction of vole sperm. Many sperm passed through the zona pellucida and invaded the

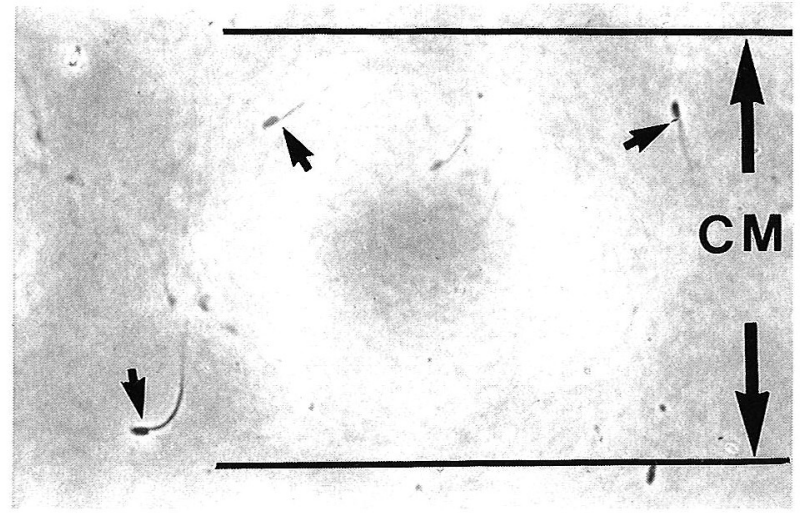

Fig. 2. Characteristic circular movement (CM) of vole sperm at $3 \mathrm{~h}$ of incubation. Arrows indicate immotile sperm. Phase-contrast microscopy. $\times 400$.

perivitelline space (Fig. 3). In intact mouse eggs with follicular cells, sperm invading the perivitelline space were recognized after $2 \mathrm{~h}$ in culture. The relative number of penetrated eggs increased with time, reaching $96 \%$ of eggs examined after 8 h. In the case of eggs without follicular cells, the zona pellucida was penetrated more rapidly than in intact eggs with follicular cells (significantly

Table 1. Penetration of the mouse zona pellucida by spermatozoa of the Japanese field vole

\begin{tabular}{|c|c|c|c|c|}
\hline \multirow{3}{*}{ Eggs } & \multicolumn{4}{|c|}{ No. of penetrated eggs/No. of eggs examined (\%) } \\
\hline & \multirow[b]{2}{*}{2} & \multicolumn{2}{|c|}{ Incubation time $(\mathrm{h})$} & \\
\hline & & 4 & 6 & 8 \\
\hline $\begin{array}{c}\text { With } \\
\text { follicular cells }\end{array}$ & $\begin{array}{l}45 / 200^{\mathrm{a}} \\
(22.5)\end{array}$ & $\begin{array}{l}95 / 228^{\mathrm{a}} \\
(41.7)\end{array}$ & $\begin{array}{c}160 / 236^{\mathrm{a}} \\
(67.8)\end{array}$ & $\begin{array}{c}217 / 226 \\
(96.0)\end{array}$ \\
\hline $\begin{array}{c}\text { Without } \\
\text { follicular cells }\end{array}$ & $\begin{array}{c}104 / 188^{\mathrm{b}} \\
(55.3)\end{array}$ & $\begin{array}{c}144 / 184^{\mathrm{b}} \\
(78.3)\end{array}$ & $\begin{array}{c}180 / 184^{\mathrm{b}} \\
(97.8)\end{array}$ & $\begin{array}{c}188 / 189 \\
(99.5)\end{array}$ \\
\hline
\end{tabular}

a, b Significantly different $\left(\mathbf{P}<0.01, \chi^{2}\right.$ test $)$

Table 2. Penetration of the hamster zona pellucida by spermatozoa of the Japanese field vole

\begin{tabular}{cccc}
\hline & \multicolumn{3}{c}{ No. of penetrated eggs/No. of eggs examined (\%) } \\
\cline { 2 - 4 } Eggs & \multicolumn{3}{c}{ Incubation time $(\mathrm{h})$} \\
\cline { 2 - 4 } & 4 & 8 & 12 \\
\hline $\begin{array}{c}\text { With } \\
\text { follicular cells }\end{array}$ & $0 / 68$ & $10 / 61^{\mathrm{a}}$ & $5 / 43^{\mathrm{a}}$ \\
Without & $(0.0)$ & $(16.4)$ & $(11.6)$ \\
follicular cells & $3 / 53$ & $59 / 82^{\mathrm{b}}$ & $42 / 49^{\mathrm{b}}$ \\
& $(5.7)$ & $(72.0)$ & $(85.7)$ \\
\hline
\end{tabular}

a, b Significantly different $\left(\mathrm{P}<0.01, \chi^{2}\right.$ test $)$ 


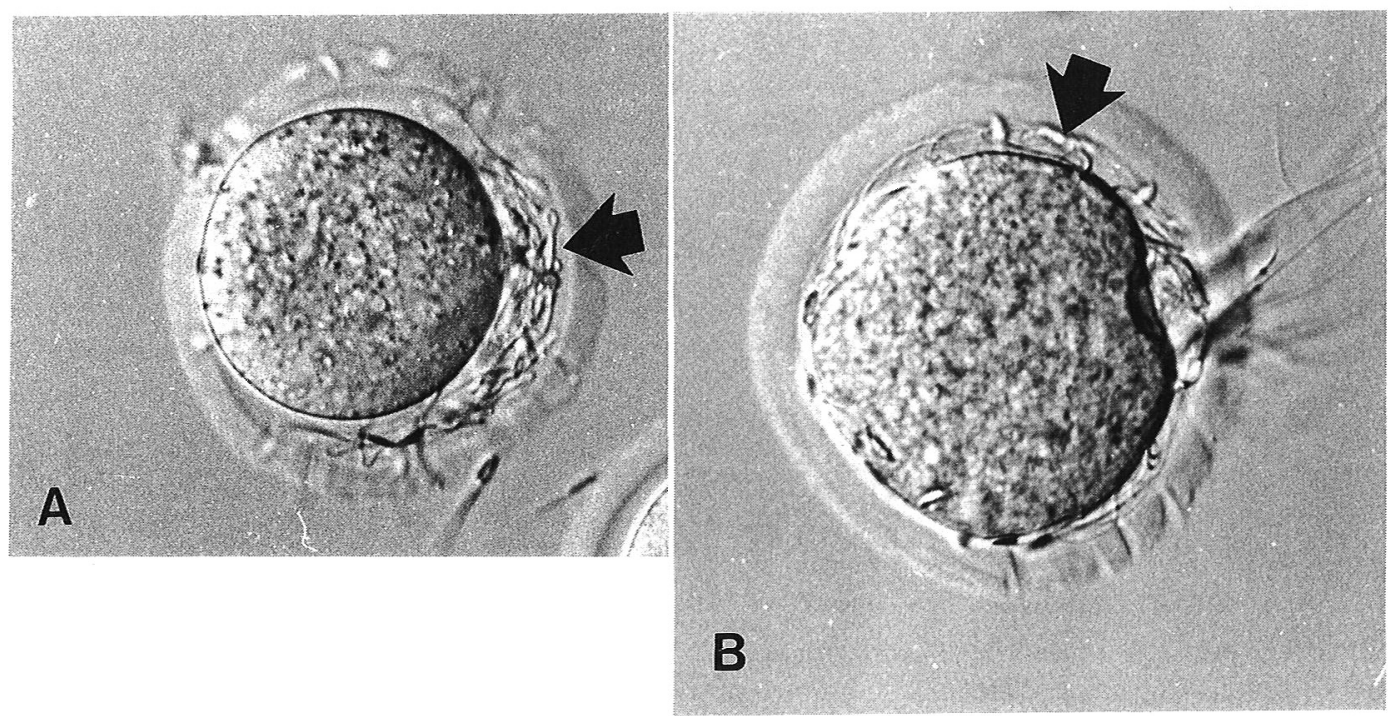

Fig. 3. A large number of sperm penetrated the perivitelline space (arrow). A: Mouse egg (4h after insemination), B: Hamster egg ( $8 \mathrm{~h}$ after insemination), Phase-contrast microscopy. $\times 200$.

different, $\mathrm{p}<0.01)$.

In contrast, the vole sperm invaded the intact hamster egg perivitelline space within $8 \mathrm{~h}$ of clture. Follicular cell-free eggs were invaded by sperm within $4 \mathrm{~h}$ in culture, reaching $85.7 \%$ of eggs examined after $12 \mathrm{~h}$.

In penetrated eggs of both the mouse and hamster, many sperm invaded the perivitelline space and some of them agglutinated there. Some penetrated eggs rotated themselves. More than two pronuclei were recognized in $1.7 \%(7 / 415)$ of the penetrated mouse eggs after $8 \mathrm{~h}$ of culture and in $16.3 \%(15 / 92)$ of the hamster eggs after $12 \mathrm{~h}$. However, neither enlarged sperm heads nor tails were recognized within the oocytes.

\section{Discussion}

No specific culture medium has yet been devised for vole sperm. However, they survived well in TYH, which was developed for mouse sperm, and in $\mathrm{mKRB}$, which was developed for rat sperm, for at least $12 \mathrm{~h}$. After $12 \mathrm{~h}, \mathrm{mKRB}$ medium was more supportive of viability and motility of the vole sperm than was TYH. The vole sperm were active and survived in vitro at concentrations of more than $1 \times 10^{8}$ cells $/ \mathrm{ml}$ (data not shown). This sperm concentration is higher than the optimal for rats $\left(0.5-1.5 \times 10^{7}\right.$ cells $\left./ \mathrm{ml}\right)[10]$ and mice $\left(1-2 \times 10^{7}\right.$ cells/ml) [9]. Hamster and porcine sperm incu- bated at a high density release a sperm motility factor (SMF) that improves the motility and capacitation of the sperm themselves [11, 12]. The observation that a high density of sperm was needed for the culture of vole sperm indicates that they too require SMF for culture in vitro and that mKRB medium is a suboptimal medium for the survival of vole sperm.

In general, sperm collected from the epididymis and those in ejaculated semen are not able to fertilize eggs at once. After a period of time in the female reproductive tract, they gain capacitation [13] and hyperactivation [14]. Sperm collected from the vole epididymis were very vigorous just after collection. The characteristic circular movements of vole sperm are similar to the movements of active sperm from cattle and sheep [15]. This circular movement is displayed only by vigorous sperm of these domestic animals and has not been recognized in other rodents. Vole sperm appear extremely vigorous in comparison to other rodents, even in mKRB medium, which is not the optimal medium.

The zona pellucida is a barrier against invasion of sperm from heterologous species. Usually only homologous sperm are able to penetrate the zona pellucida, and only one sperm is allowed to enter the oocyte and fertilize the egg. Other sperm are excluded by the zona reaction [1]. Penetration of the zona of heterologous eggs was reported for deer mouse and laboratory mouse sperm $[5,6]$. 
Fukuda $e t$ al. suggested that the zona was dissolved by some enzyme associated with the sperm. Deer mouse sperm pass through the zona of mouse eggs and invade the perivitelline space, but they do not enter the cytoplasm of the oocyte. In this case, the vitelline membrane also plays a role as a barrier that prevents entry of sperm into the cytoplasm. However, zona-free hamster eggs are invaded by heterologous sperm [16].

As revealed in the present study, vole sperm were able to penetrate the zona of mouse and hamster eggs at a high rate. Many vole sperm were recognized in the perivitelline space, but there was no sign of sperm entry into the egg cytoplasm, such as tails or enlarged heads of sperm. Of the penetrated eggs, $1.7 \%$ of mouse and $16.3 \%$ of hamster eggs contained more than 2 pronuclei. However, these pronuclei were considered female depending on parthenogenetics becaue no extru- sion of the second polar body was recognized.

In normal mouse fertilization, most eggs are penetrated by sperm during a restricted and brief time after insemination [17]. By contrast the present study, the numbers of penetrated mouse and hamster eggs increased with time after insemination with vole sperm. Although vole sperm were extraordinarily vigorous, enzymatic action was not examined. Therefore, it is not clear whether vole sperm penetration depends on vigorous movement and/or enzymatic action, the physiological admission of sperm for fertilization called acrosome reaction [18].

The extraordinary activity of vole sperm suggests that future studies with eggs of other species may be fruitful. Furthermore, penetration of the zona by vole sperm merits examination as a possible biological tool.

\section{References}

1. Wassarman PM. Zona pellucida glycoproteins. Ann Rev Biochem 1988; 57: 415-442.

2. Yanagimachi R. Penetration of guinea-pig spermatozoa into hamster eggs in vitro. J Reprod Fert 1972; 28: 477-480.

3. Hanada A, Chang MC. Penetration of zona-free eggs by spermatozoa of different species. Biol Reprod 1972; 6: 300-309.

4. Hanada A, Chang MC. Penetration of hamster and rabbit zona-free eggs by rat and mouse spermatozoa with special reference to sperm capacitation. $J$ Reprod Fert 1976; 46: 239-241.

5. Fukuda Y, Maddock MB, Chang MC. In vitro fertilization of two species of deer mouse eggs by homologous or heterologous sperm and penetration of laboratory mouse eggs by deer mouse sperm. J Exp Zool 1979; 207: 481-490.

6. Hanada A, Chang MC. Penetraton of the zona-free or intact eggs by foreign spermatozoa and the fertilization of deer mouse eggs in vitro. J Exp Zool 1978; 203: 277-286.

7. Imai S, Ogimoto K. Flagellate protozoa in the digestive tract of the Japanese field vole, Microtus montebelli. Jpn J Zootech Sci 1988; 59: 351-356.

8. Obara $\mathbf{Y}$, Goto $\mathbf{N}$. Utilization of endogenous nitrogen in Japanese field vole (Microtus montebelli). Jpn J Zootech Sci 1988; 59: 733-739.

9. Toyoda Y, Yokoyama M, Hosi T. Studies on the fertilization of mouse eggs in vitro. 1 . In vitro fertilization of eggs by fresh epididymal sperm. Jpn J Animal Reprod 1971a; 16: 147-151.
10. Toyoda Y, Chang MC. Fertilization of rat eggs in vitro by epididymal spermatozoa and the development of eggs following transfer. J Reprod Fert 1974; 36: 9-22.

11. Bavister BD, Yanagimachi R. The effects of sperm extracts and energy sources on the motility and acrosome reaction of hamster spermatozoa in vitro. Biol Reprod 1977; 16: 228-237.

12. Nagai $\mathbf{T}$, Niwa $\mathbf{K}$, Iritani A. Effect of sperm concentration during preincubation in a defined medium on fertilization in vitro of pig follicular oocytes. J Reprod Fert 1984; 70: 271-275.

13. Chang MC. Fertilizing capacity of spermatozoa deposited into the fallopian tubes. Nature 1951; 168: 697-698.

14. Yanagimachi R. The movement of golden hamster spermatozoa before and after capacitation. $J$ Re prod Fert 1970; 23: 193-196.

15. Rothschild. Measurement of sperm activity before artificial insemination. Nature 1949; 163: 358-359.

16. Yanagimachi R. Zona-free hamster eggs: their use in assessing fertilizing capacity and examining chromosomes of human spermatozoa. Gamete Res 1984; 10: 187-232.

17. Toyoda Y, Yokoyama M, Hosi T. Studies on the fertilization of mouse eggs in vitro. 2. Effects of in vitro pre-incubation of spermatozoa on time of sperm penetration of mouse eggs in vitro. Jpn J Animal Reprod 1971b; 16: 152-157.

18. Austin CR, Bishop MWH. Role of the rodent acrosome and perforatorium in fertilization. Proc Roy Soc Lond Ser B 1958; 149: 241-248. 